\title{
Evaluation of Fatigue Damage in Adhesive Bonding: \\ Part 1: Bulk adhesive
}

\author{
M.M. Abdel Wahab ${ }^{1, *}$, I. Hilmy ${ }^{2}$, I.A. Ashcroft ${ }^{3}$ and A.D. Crocombe ${ }^{2}$ \\ ${ }^{1}$ Department of Mechanical Construction and Production, Faculty of Engineering, Ghent \\ University, B-9000 Gent, Belgium \\ ${ }^{2}$ Faculty of Engineering and Physical Sciences, University of Surrey, Guildford, Surrey, \\ GU2 5XH, UK \\ ${ }^{3}$ Department of Mechanical Engineering, Loughborough, Leicestershire, LE11 3TU, UK
}

*Corresponding author: Prof. Dr. Ir. Magd Abdel Wahab, e-mail: magd.wahab@ugent.be

\begin{abstract}
The measurement of damage constants in adhesive bonding has been investigated. Bulk adhesive was used in this study for two reasons: a) stress distribution in bulk adhesive is simpler than adhesive in joints and b) specimen dimensions met fatigue test standard. Bulk adhesive was made from film-form of epoxy resin. In general, the characteristics and the behaviour of bulk adhesive may differ from adhesive in joint because of the presence of voids and the constrains imposed by the substrates. Low cycle fatigue tests with load amplitude ratio of 0.1 at frequency $5 \mathrm{~Hz}$ were performed to determine the damage variable as a function of number of cycles. Damage curves, i.e. evolution of damage variable as a function of number of cycles, were derived and plotted using isotropic damage equation. Damage was evaluated using the decrease of stress range during lifecycles of a constant displacement amplitude test. It was found that damage curves were fitted well by low cycle fatigue damage evolution law equation. This equation was derived from a dissipation potential function. Curve fitting was performed using Robust Least Square rather than ordinary linear least square because damage curves have extreme points (usually near failure point). It was found that fitting process could not converge for adhesive fracture at higher cycles ( $\mathrm{Nf}>9000)$. Two damage constants $A$
\end{abstract}


and $\beta$ were found from the fitting process. Each fatigue set of data, at a certain level of von Mises stress range for undamaged state or at stabilization of harding stress $\left(\Delta \sigma_{e q}^{*}\right)$, has different set of damage parameters $A$ and $\beta$. Linear regression of these points was used to express $A$ and $\beta$ as a function of $\Delta \sigma_{e q}^{*}$. Using these expressions, damage curves for different levels of $\Delta \sigma_{e q}^{*}$ could be predicted.

Keywords: Continuum Damage Mechanics, Damage parameters, Low Cycle fatigue, Bulk Adhesive, Crack Initiation, lifetime prediction

\section{Introduction}

The definition of Adhesive bonding is a process of joining two parts/structures using non-metallic material (adhesive) [1]. This bonding undergoes chemical and physical hardening reaction causing parts to be jointed together through surface adherence (adhesion) and internal strength (cohesion). For most adhesive systems, adhesive is the weakest material because the attractive force between adhesive and substrate (adhesion) is stronger compared to the force within the adhesive layer (cohesion). Usually the internal strength of substrate and adhesive could be controlled. Strength of substrate can be controlled from its manufacturing process. Strength of adhesive can be controlled by adjusting the process of heating and curing time. But if the area of contact (interface) became the weakest part because of imperfect contact process, then the joint strength will decrease. As a result, failure at lower load or non-uniform strength along bondline will take place. 
Many mechanical failure modes might take place in adhesive systems. This failure can happen to a system with simple to complex configurations. It is estimated that between $50-90 \%$ of the failure caused by fatigue [2].

In 1870, Wohler as cited by Blaum [3] is the first researcher who performed systematic research of fatigue life with train chassis as object. He investigated material behaviour under constant loading amplitude. Structure behaviour under specific load for various different materials has been investigated experimentally and numerically afterwards. Fatigue crack growth has been understood to some extent but the phenomenon of crack initiation has not yet been fully understood.

Low cycle fatigue failure has the following characteristics: (1) structure suffers high load, (2) lives are relatively short and (3) significant plastic straining takes place. Failure caused by low cycle fatigue load takes place in structures subjected to heavy load. This load induces irreversible strain at micro-scale or macro-scale. Damage accumulation in a structure will reach the point of initiation and propagation of cracks. A cycle is usually defined as an interval between two services time. Number of cycles to failure $\left(N_{f}\right)$ is relatively small. Lemaitre and Desmorat [4] have categorized the classification of low cycle fatigue as follows:

1. The value of $N_{f}$ lies between $10-100$ for aerospace rocket or metal forming by forging. Stresses are between $\sigma_{\mathrm{u}}>\sigma>\sigma_{\mathrm{y}}$, where $\sigma_{\mathrm{u}}$ is the ultimate stress and $\sigma_{\mathrm{y}}$ is the yield stress.

2. The value of $N_{f}$ lies between 100 - 1000 for thermal or nuclear power plant, chemical plant. Stresses are slightly larger than yield stress. 
3. The value of $N_{f}$ lies between 1000 - 10000 for aircraft engines or car engines where stresses induce plastic strain with magnitudes approaching $\varepsilon_{p} \approx \sigma_{y} / E$, where $\varepsilon_{p}$ is the plastic strain and E is Young's modulus.

The damage model presented in this paper makes use of low cycle fatigue model, which is based on accumulation of plastic strains. The low cycle fatigue damage model is mainly considered when the plastic strain is high enough to be measured. In such a case, the stresses should be higher than the yield stress of the material and the number of cycles to failure corresponds to less than or equal to 10000 cycles. If the number of cycles to failure is too high, say more than 100000 cycles, the plastic strain is at micro size and not measurable, and therefore the low cycle fatigue model is not applicable. It is worth mentioning that because structural adhesive joints always contain stress singularity points, the stresses are singular, i.e. exceed the elastic limit and plastic zones take place around these points. Therefore, low cycle fatigue damage model is always suitable for adhesive joints regardless the number of cycles to failure.

Basic characteristic of low cycle fatigue is based on Coffin- Manson equation as described in [5]. Figure 1 shows a typical Coffin-Manson Curve. The approximated equation for Coffin-Manson is given by:

$$
N_{f}=\left(\frac{C_{m c}}{\Delta \varepsilon_{p}}\right)^{\gamma}
$$

Where $C_{m c}$ and $\gamma$ are material parameters: $C_{m c}$ depends on temperature but $\gamma$ is close to 2 regardless the type of material and temperature. Total strain amplitude can be calculated as follows [6]: 


$$
\frac{\Delta \varepsilon_{T}}{2}=\frac{\Delta \varepsilon_{e}}{2}+\frac{\Delta \varepsilon_{p}}{2}=\frac{\sigma_{f}^{\prime}}{E}\left(2 N_{f}\right)^{b}+\varepsilon_{f}^{\prime}\left(2 N_{f}\right)^{c}
$$

Where $\frac{\Delta \varepsilon_{e}}{2}=$ elastic strain amplitude,

$$
\begin{aligned}
& \frac{\Delta \varepsilon_{p}}{2}= \text { plastic strain amplitude, } \\
& \sigma_{f}^{\prime}= \text { fatigue strength coefficient, defined by the stress intercept at one load } \\
& \text { reversal (see Figure 1), } \\
& \varepsilon_{f}^{\prime}= \text { fatigue ductility coefficient, defined by the strain intercept at one load } \\
& \text { reversal, } \\
& 2 N_{f}= \text { total number of reversals to failure, } \\
& b \text { and } c=\text { fatigue ductility exponent (material properties). }
\end{aligned}
$$

Nowadays, there is still a debate among researchers about which mechanism has the most contribution in joint lifetime; crack initiation or crack propagation. The problem is that it is not straightforward to prove which mechanism is dominant. Different ratios crack initiation to crack propagation lifetimes can be found depending on how crack initiation is defined, measured and what techniques are used in order to monitor crack propagation. Researchers have also found that modifying geometry and fracture property may lead to different results.

There are two common techniques in order to observe damage and cracks in adhesive joints: namely video microscopy and back-face strain technique. Courta et al. [7] used transparent Polymethyl Methacrylate Adherends (PMA) so that the crack propagation inside joints can be observed visually using video camera. It was concluded that crack initiation dominate the joint lifetime before its failures. Harris and Fay [8] used 
video microscopy to observe side of single lap joint for automotive application and to identify crack initiation. Again, it was found that fatigue lifetime was dominated by crack initiation. Back-face strain technique has been used and extended by several researchers: e.g. Zhang et al. [9], Imanaka et al. [10] and Crocombe et al. [11].

Crocombe et al. [11] have found two conclusions. Firstly, for adhesive joints with fillet, more than $50 \%$ of the lifetime is dominated by crack initiation. When the fillet is removed, joint lifetime decreases significantly and crack initiation period is almost zero. Secondly, the ratio of crack initiation lifetime to propagation lifetime increases as the load level decreases. Marcadon et al. [12] has studied durability of vinyl ester adhesive T-joint for a structural part of a ship. After careful observation of cracking mechanism, it was found that the crack propagation of T-joints dominated about two third of fatigue failure lifetime. Using back-face strain method, Zhang et al. [9] has found that the ratio of crack initiation to crack propagation lifetimes of single lap joints was not constant.

There were cases where different experimental results for crack initiation have been found for the same adhesive/substrate joint system. For example, for the same adhesive system, Crocombe [13] and Curley et al. [14] have found crack initiation phase less than $60 \%$ and $15 \%$, respectively. For this test, Curley et al [14] used specimen with spew-fillet and the results were observed using back-face strain method of the same dimension size. Crocombe used specimen with controlled fillet and observed crack initiation using video microscopic [13].

The main aim of the first part of this paper is to measure crack initiation damage parameters of adhesives using bulk adhesive test specimens. The damage parameters, which are function of stress level in adhesives, are extracted by fitting the experimental 
data to damage evolution law. In the second part of this paper, the technique is further extended and applied to adhesive in joint, namely a Single Lap Joint, in order to include the effect of triaxiality function on the damage parameters and the prediction of crack initiation lifetime.

\section{Experimental set-up}

Bulk adhesive specimens were used in this experiment as a first step to determine the fatigue damage parameters. It has the advantage that the interpretation of stress-strain data of bulk adhesive is easier than adhesive in joints. Bulk adhesive has simpler stress distribution because of the absence of substrates [15]. The specimens were made from epoxy resins, FM-73 film adhesives supplied by Cytec ${ }^{\mathrm{TM}}$. Epoxy resins are a class of versatile thermosetting polymers and are extensively used in structural adhesives for polymer composites. This is because of their high strength, low creep, very low cure shrinkage, excellent resistance to corrosion, good adhesion to many substrates and appropriate electrical properties [16].

The placement of bulk adhesive along with its support apparatus is shown in Figure 2. The function of weighing mass is to give pressure to the Upper glass plate, which will be transferred to bulk adhesive. The use of reference thickness plate is to stop reducing adhesive thickness during heating and pressuring process. Stopper is used to avoid sliding movement of upper glass. If sliding movement happens, it will cause adhesive to tear.

There are two possibilities for air to emerge inside bulk adhesive. Firstly, air may trap during film manufacturing process. Secondly, air may trap during bulk adhesive 
manufacturing. The higher number of stacking layers, the bigger possibility of the amount of trapped air bubbles. This phenomenon is shown in Figure 3.

To minimize the chance of air bubble forming, the following process was performed. In the beginning, for every four layers, pressure was applied using pressure roller. The result is shown in Figure 4 (a). There were voids at first manufacturing process. To improve the quality of bulk adhesive, after stacking every single layer, pressure was applied. The result is shown in Figure 3(b). Even by increasing the pressure, voids are still present. Voids act as stress raiser or stress concentrator to promote premature failure. It is concluded that the real bulk adhesive strength might differ from the adhesive model in the joint since the presence of void could be different.

There were two types of experiments that have been performed; namely tensile tests and fatigue tests. Tensile tests make use of the machine Instron 5500R, frame 6025 with the following characteristics: maximum load range is $100 \mathrm{kN}$, cross-head displacement rate from 0.001 up to $1000 \mathrm{~mm} /$ minute and controlled by MERLIN software [17]. Fatigue tests have been carried out using Instron 8511 Test System. The model 8511 is a compact servo-hydraulic material testing system designed for linear dynamic test forces for specimens from a wide range of materials. This machine is controlled by built-in software called MAX. Figure 4 shows the Instron 8511 machine and the test set-up. Figure 6 (a) shows a picture of the bulk adhesive test specimens and Figure 6 (b) shows its dimensions. The specimen has been machined in the mechanical workshop at the University of Surrey.

To obtain the equivalent stress as a function of time or cycles, low cycle fatigue (LCF)-strain based test of bulk adhesive was performed. Triangular strain shape was 
chosen because of its linear shape. Although the turning point is sharp, the effect is small since the test is carried out at low frequency. The minimum displacement is $0.24 \mathrm{~mm}$, maximum displacement is $1.4 \mathrm{~mm}$ and test frequency is $5 \mathrm{~Hz}$.

Tensile test is performed in order to obtain material parameters, which is needed for damage evolution formula and finite element analysis. The tests were performed by controlling the extension (extension rate $=0.016 \mathrm{~mm} / \mathrm{sec}$ ) of specimens up to its failure, while the load is recorded. Direct results were presented in form of load as a function of extension. This curve was then converted to engineering stress-strain curve by dividing force and extension by cross-sectional area and initial length of specimen, respectively. Stress-strain curve was fitting to Ramberg-Osgood formula [18]. The curve fitting process was performed using the facility 'Cftool' provided in MATLAB. The result is shown in Figure 7. From curve fitting process, the material properties of the bulk adhesive were obtained as; $E=1160 \mathrm{~N} / \mathrm{mm}^{2}, K=61.437 \mathrm{~N} / \mathrm{mm}^{2}$ and $m=0.08$, where $E$ is Young's modulus and $K$ and $m$ are Ramberg-Osgood parameters.

Several low cycles fatigue tests have been performed. Some specimens were eliminated for inconsistence results. This was because the specimen had void greater than the average. The result is shown in Figure 8 as strain range $\Delta \varepsilon(\%)$ versus number of cycles to failure $N_{f}$ in logarithmic scale. This is Manson-Coffin curve form.

In Figure 9, the measured load as a function of number of cycles is shown. It shows the decrease in maximum and minimum loads after each cycle. A decrease in stress range would indicate a degradation of stiffness during lifetime. This is a characteristic of constant strain (or displacement) amplitude fatigue test. 


\section{Damage Measurement Based on Stress Degradation}

Stress degradation occurs during strain-based controlled test. To obtain the damage variable $(D)$ as a function of number of cycles, applied stress range and triaxiality, one should develop damage equation based on thermodynamics principles as developed by Wahab et. al. [19], i.e.:

$$
D=1-\left[1-A(\beta+m+1)\left(\Delta \sigma_{e q}\right)^{\beta+m} R_{V}^{\beta / 2} N\right]^{\frac{1}{\beta+m+1}}
$$

Where $D$ is the damage variable, $N$ is the number of cycles, $\Delta \sigma_{e q}$ the range of von-Mises stress, $R_{V}$ the triaxiality function, $m$ the power constant in Ramberg-Osgood equation, and $A$ and $\beta$ are damage parameters to be determined experimentally. It should be noted that $\Delta \sigma_{e q}$ is the applied stress range at the beginning of the fatigue cycles. Thus, in case of constant displacement amplitude test, the stresses decrease as function of number of cycles and $\Delta \sigma_{e q}$ should be replaced by $\Delta \sigma_{e q}^{*}$, which is vonMises stress range for virgin material or at stabilization of harding (see later Equation (9)).

Figure 10 shows the model proposed by Voyiadjis and Kattan [20]. Two equivalent models of a damaged bar have been compared. The first bar has cracks and micro-voids (Figure 10 (a)), while the second one has neither cracks nor voids, i.e. voids and cracks are removed from the first bar (Figure 10 (b)). The second bar has a crosssectional area $\bar{A}=A_{T}-A_{D}$ (where $A_{T}$ is the total cross-sectional area and $A_{D}$ is the cracks and micro-voids cross-sectional area), which means the area has been reduced after the removal of voids and micro-cracks. A uniaxial fatigue load range $\Delta T$ is applied to both 
rods. Stress range in the damaged state is denoted as $\Delta \sigma$, while stress range in the undamaged state is denoted as $\Delta \sigma^{*}$. If the same fatigue load range $\Delta T$ is applied for both damaged and undamaged models, it is calculated as:

$$
\begin{aligned}
& \Delta T=\Delta \sigma A_{T}, \text { for first bar (with damage) } \\
& \Delta T=\Delta \sigma^{*} \bar{A}=\Delta \sigma^{*}\left(A_{T}-A_{D}\right), \text { for second bar (without damage) }
\end{aligned}
$$

Since $\Delta T$ from Equation 4 is equal to $\Delta T$ from Equation 5 , i.e.

$$
\Delta \sigma A_{T}=\Delta \sigma *\left(A_{T}-A_{D}\right)
$$

Equation 6 is arranged so that:

$$
\Delta \sigma=\Delta \sigma *\left(1-\frac{A_{D}}{A_{T}}\right)
$$

Substituting $\mathrm{A}_{\mathrm{D}} / \mathrm{A}_{\mathrm{T}}$ by $D$, Equation 7 becomes:

$$
\Delta \sigma=\Delta \sigma *(1-D)
$$

Finally Damage variable $D$, is defined as:

$$
D=1-\frac{\Delta \sigma}{\Delta \sigma^{*}}
$$

In order to determine the damage parameters $\mathbf{A}$ and $\boldsymbol{\beta}$, Equation (3) is simplified in a polynomial form as follows:

Two constants $C_{1}$ and $C_{2}$ are defined as:

$$
(\beta+m+1) A\left(\Delta \sigma_{e q}\right)^{\beta+m} R_{V}^{\beta / 2}=C_{1} \text { and } \beta+m+1=C_{2}
$$

Equation 3 becomes

$$
D=1-\left[1-C_{1} N\right] \frac{1}{C_{2}}
$$

Re-arranging Equation (11) gives: 


$$
1-D=\left[1-C_{1} N\right] \frac{1}{C_{2}}
$$

Let $1-D=D_{m}$ and powered both sides by $\mathrm{C}_{2}$, leads to:

$$
D_{m}^{C_{2}}=1-C_{1} N
$$

Re-writing Equation 13 as:

$$
\frac{1}{C_{1}} D_{m}{ }^{C_{2}}-\frac{1}{C_{1}}=-N
$$

If $1 / C_{1}=K_{1}$, a simpler form of the damage equation is obtained as:

$$
N=K_{1}-K_{1} D_{m}^{C_{2}}
$$

$K_{1}$ and $C_{2}$ values can be obtained by performing curve fitting of Equation 15 to damage experimental data. Fitting process was performed using 'cftool' command provided in MATLAB. This command uses Trust-region algorithm, which is an improvement of Levenberg-Marquardt algorithm and implements Least Absolute Residuals (LAR) method. Fitting using LAR method for this case is better than Least Square (LS) because LS is more sensitive for extreme values (outliers) [21]. With Trustregion algorithm, nonlinear problem can be solved more efficiently comparing to other algorithm. The MATLAB code for curve fitting of Equation (15) to experimental data is given in Appendix A.

Referring to Equation (3), since damage calculation only needs maximum and minimum load values (to calculate the von-Mises stress range and the average triaxiality function), those values could be extracted from fatigue raw data. To extract the required data, an algorithm has been implemented in MATLAB. Result of fatigue data extraction is shown in Figure 11. Curve is formed from peak points connected from one cycle to the 
next cycle. The decrease in maximum or minimum loads is made clear after converting the raw data.

The advantage of this data extraction process is that huge amount of data obtained from fatigue test can be significantly reduced. Computing time can also be reduced. The next step is to calculate the difference between maximum and minimum loads. This value is called $\Delta L$ (fatigue load range at a certain damage state) corresponding to $\Delta \sigma_{e q}$ (vonMises stress range at a certain damage state).

Using linear regression of stabilize region which is intersected with load axis, $\Delta L^{*}$ (fatigue load range at undamaged state or at stabilization of harding as shown in Figure 12) can be determined. From Equation 9, since the total cross-sectional area is constant during its lifecycle, damage can be calculated as:

$$
D=1-\frac{\Delta L}{\Delta L^{*}}
$$

The result of equation 16 is shown in Figure 13. Damage started from zero as it is always assumed that at the beginning of test material is in its virgin state. It is shown that damage variable increased slightly, and then suddenly rose sharply at failure. (sudden death). Next, since $D_{m}$ is equal to $1-D$, curve of $D$ versus number of cycles can be converted to $D_{m}$ versus the number of cycles $(N)$. This new curve is shown in Figure 14. Equation 3 (using its simple form in equation 5) will be fitted to this curve in order to obtain the damage parameters $A$ and $\beta$.

Several attempts to fit curve $N$ versus $D_{m}$ directly have been unsuccessful. It is because there are no enough points near failure. Mathematically, the weight of the data is 
uneven. To overcome this problem, several points were added in-between the last and second last points as shown in Figure 15. Adding these points is valid with the assumption that from the second-last point to the last point, the change in $D_{m}$ is linear.

After adding several points, the curve fitting process can be successfully performed. Figure 16 shows fitted curve compared to the original data. Since the fitted curve is a continuous function, it is shown that damage variable has smoothly increased near failure (the last point). From the fitting process, two parameters were found: $K_{1}=$ 98.8 and $\mathrm{C}_{2}=13.26$ with $95 \%$ of confidence bounds. Goodness of fit: SSE (the sum of squared errors (residuals)): 354.2, R-square (the ratio of the sum of squares of the regression (SSR) and the total sum of squares (SST)): 0.9867, Adjusted R-square (adjustment based on the residual degrees of freedom): 0.9862 and RMSE (Root Mean Squared Error): 3.622. After $K_{1}$ and $C_{2}$ were found, damage parameter $A$ and $\beta$ can be calculated and the values are as follows: $A=6.01 \times 10^{-20} \mathrm{E}-20, \beta=9.391$. With the same technique, $A$ and $\beta$ for different $\Delta \sigma_{e q}^{*}$ (von Mises stress range at stabilization of harding or at undamaged state) have been calculated and listed in Table 1. Plot A and $\beta$ versus $\Delta \sigma_{e q}^{*}$ are shown in Figure 17 and Figure 18. From both figures, it is shown that $A$ has tendency to decrease, while $\beta$ to increase. Finally, damage from experiments (calculated by using Equation 9) is compared to damage from prediction (plotted by using Equation 3) in Figure 19. For other tests, using the same procedures (for different $\Delta \sigma_{e q}^{*}$ ), different values of $A$ and $\beta$ have been found. The predicted damage curves are compared to the experimental damage curves in Figure 20. 
Fatigue tests with higher cycles to failure $\left(N_{f}>10000\right.$ cycles $)$ were performed. The damage evolution law could not be fitted to the damage experimental curves because the fitting process failed to converge. The highest number of cycles to failure, for which the fitting process converged, was $N_{f}=9401$.

\section{Conclusions}

From the application of fatigue crack initiation damage evolution law to bulk adhesive test specimens, the following conclusions have been made:

1. Bulk adhesive was suitable for initial determination of damage parameters, where triaxiality function is equal to one.

2. The damage parameters have been successfully extracted from the experimental data though curve fitting using the damage evolution low.

3. Additional data have been inserted into damage curve for fitting process of damage evolution curve without changing its physical meaning. The aim was to weigh the data near failure so that the fitting process could easily converge.

4. Procedure to obtain the damage parameters $A$ and $\beta$ of bulk adhesive has been proposed. With this procedure, damage curve for different stress levels could be predicted. The fitting process only converges for low cycle fatigue failure in these cases less than 10000 cycles. Since the experimental tests were performed on bulk adhesive specimens, the applicability of low cycle fatigue may be limited to 10 000 cycles. However, since structural adhesive joints contain stress singularity points, low cycle fatigue damage model is always suitable for adhesive joints 
regardless the number of cycles to failure because the stresses exceed the elastic limit and plastic zones take place around these singularity points.

Further application of the technique to adhesive in joints will be presented in part 2 of this paper, where multi-axial stress state and triaxiality function are considered in more details.

\section{References}

1. S.K. Mazumdar, Composite Manufacturing: Materials, Product And Process Engineering, CRC Press (2002).

2. S.P. Timoshenko, History of Strength of Materials, Donner Publication (1982).

3. R. Blaum, August Wöhler in Beiträge zur Geschichte der Technik und Industrie, 8,33 (1918).

4. J. Lemaitre and R. Desmorat, Engineering Damage Mechanics, Springer-Verlag (2005).

5. V.M. Radhakrisnan, On Bilinearity of Manson-Coffin Low Cycle Fatigue Relationship, NASA Technical Memorandum 105840, October (1992).

6. J. Lemaitre and J.L. Chaboche, Mechanics of Solid Materials, Cambridge University Press (1998).

7. R.S. Courta, M.P.F. Sutcliffe and S.M. Tavakoli, Int. Journal of Adhesion \& Adhesives, 21, 455 (2001).

8. J.A. Harris and P.A. Fay, Int. Journal of Adhesion and Adhesive, 12, 9 (1992).

9. Z. Zhang, J.K. Shang and F.V. Lawrence, Journal of Adhesion, 49, 23 (1995).

10. M. Imanaka, K. Haraga and T. Nishikawa, Journal of Adhesion, 49, 197 (1995). 
11. A.D. Crocombe, C.Y. Ong, C.M. Chan, M.M. Abdel Wahab and I.A. Ashcroft, Journal of Adhesion, 78, 745 (2002).

12. V. Marcadon, Y. Nadot, A. Roy and J.L. Gacougnolle, Int. Journal of Adhesion \& Adhesives, 26, 481 (2006).

13. A.D. Crocombe, Proceedings of Structural Adhesives in Engineering V (SAE V). Bristol: Institute of Materials; pp. 80 (1998).

14. A.J. Curley, H. Hadavinia, A.J. Kinloch and A.C. Taylor, Int. Journal of Fracture, 103, 41 (2000).

15. G. Dean and B. Duncan, Preparation and testing of bulk specimens of adhesives, NPL Measurement Good Practice Guide No 17 (1998).

16. L.F.M. da Silva, R.D. Adams and M. Gibbs, Int. Journal of Adhesion \& Adhesives, 24, 69 (2003).

17. User Manual, Instron 5500R frame 6025 (1992).

18. W. Ramberg and W.R. Osgood, Description of Stress-Strain Curves by Three Parameters. Technical Note No. 902, National Advisory Committee For Aeronautics, Washington DC, (1943).

19. M.M. Abdel Wahab, I.A. Ashcroft, A.D. Crocombe and S.J. Shaw, Journal of Adhesion Science Technology, 15, 763 (2001).

20. G.Z. Voyiadjis and P.I. Kattan, Advances in Damage Mechanics: Metals and Metals Matrix Composites, Elsevier, Oxford, (1999).

21. User Guide, MATLAB ver 7.1, Mathworks Inc. (2004). 
Table 1: Damage Parameters $A$ and $\beta$ for different range of von-Mises stress at stabilization of harding $\left(\Delta \sigma_{e q}^{*}\right)$

\begin{tabular}{|c|c|r|c|c|c|c|c|}
\hline $\begin{array}{c}\Delta \text { disp. } \\
(\mathrm{mm})\end{array}$ & $\begin{array}{c}\Delta \sigma_{e q}^{*} \\
(\mathrm{MPa})\end{array}$ & \multicolumn{1}{c|}{$N_{\mathrm{f}}$} & \multicolumn{1}{|c|}{$K_{1}$} & \multicolumn{1}{c|}{$C_{2}$} & $\boldsymbol{\beta}$ & $C_{1}$ & $A$ \\
\hline 1.40 & 44.18 & 10 & 9.724 & 11.76 & 10.68 & $1.03 \times 10^{-1}$ & $1.73 \times 10^{-20}$ \\
\hline 1.29 & 43.88 & 99 & 101.3 & 13.79 & 12.71 & $9.87 \times 10^{-3}$ & $7.08 \times 10^{-25}$ \\
\hline 1.11 & 43.15 & 179 & 181.5 & 15.75 & 14.67 & $5.51 \times 10^{-3}$ & $2.68 \times 10^{-28}$ \\
\hline 1.09 & 41.94 & 418 & 424.4 & 14.74 & 13.66 & $2.36 \times 10^{-3}$ & $8.11 \times 10^{-27}$ \\
\hline 0.92 & 34.6 & 9401 & 9557 & 26.39 & 25.31 & $1.05 \times 10^{-4}$ & $3.32 \times 10^{-45}$ \\
\hline
\end{tabular}

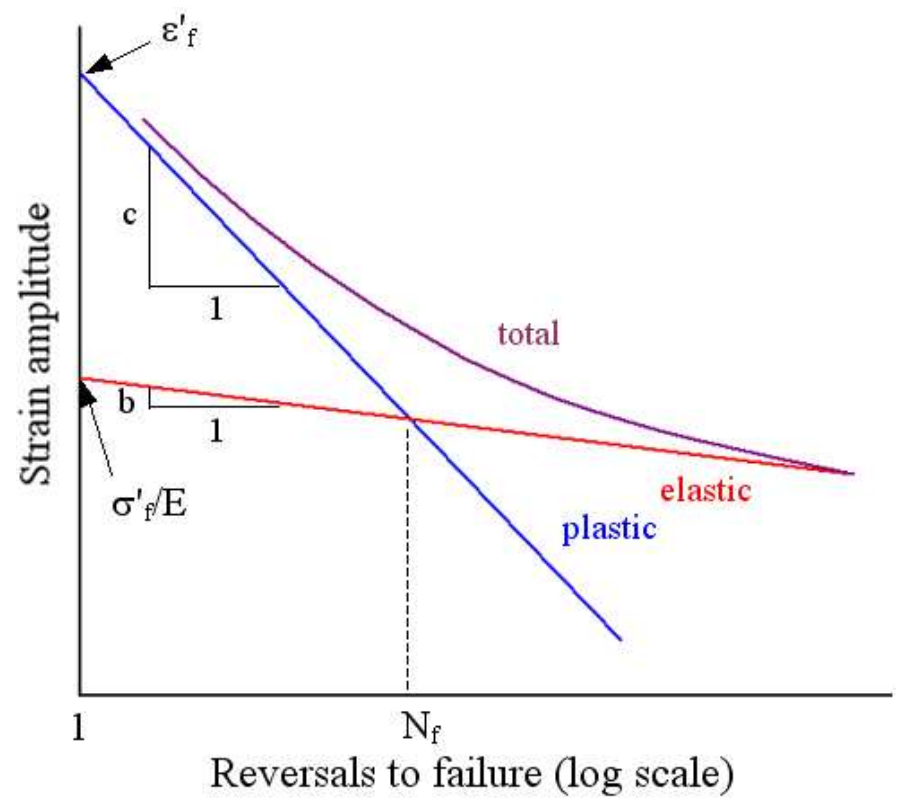

Figure 1: Typical joint lifetime according to Coffin-Manson's equation, adapted from Onem [6] 
1. Weighing mass

2. Upper glass plate

3. Stopper (1 each plate side)

4. Bulk adhesive

5. Reference thickness

6. Base glass plate

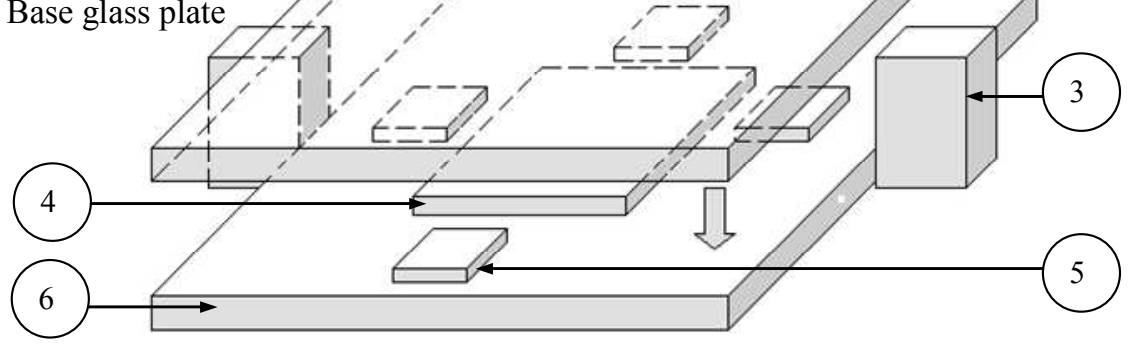

Figure 2: Specimen placement to perform heating process.

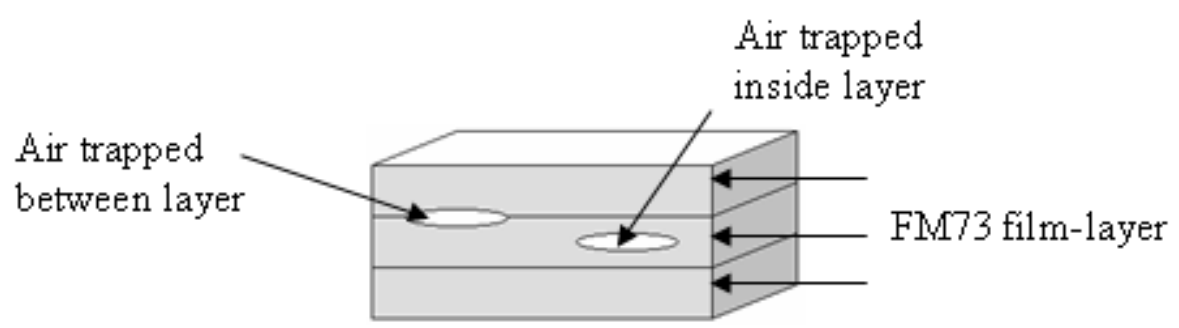

Figure 3: Trapped air bubble inside bulk adhesives 


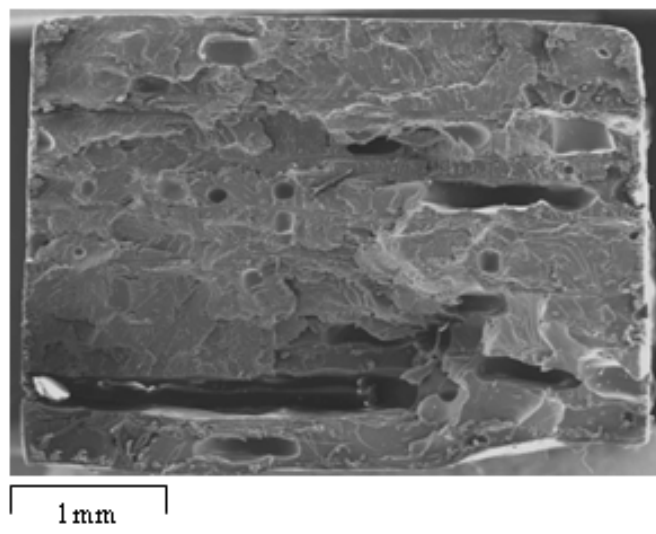

(a)

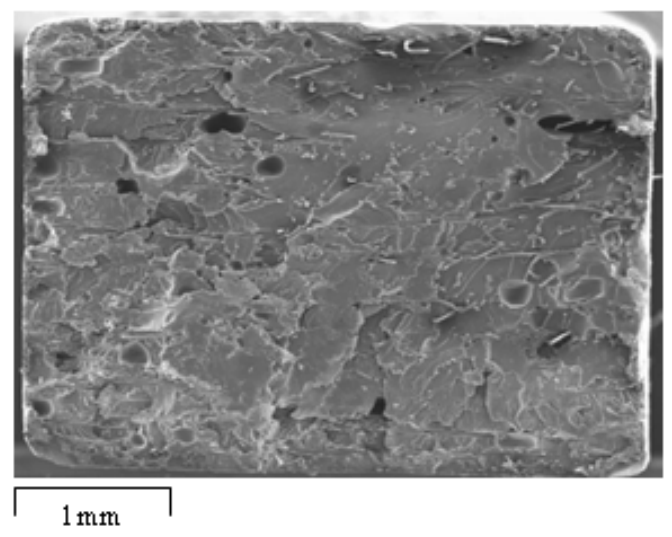

(b)

Figure 4: Fracture surface of FM-73 bulk adhesive; (a) Before,

(b) After manufacturing improvement.

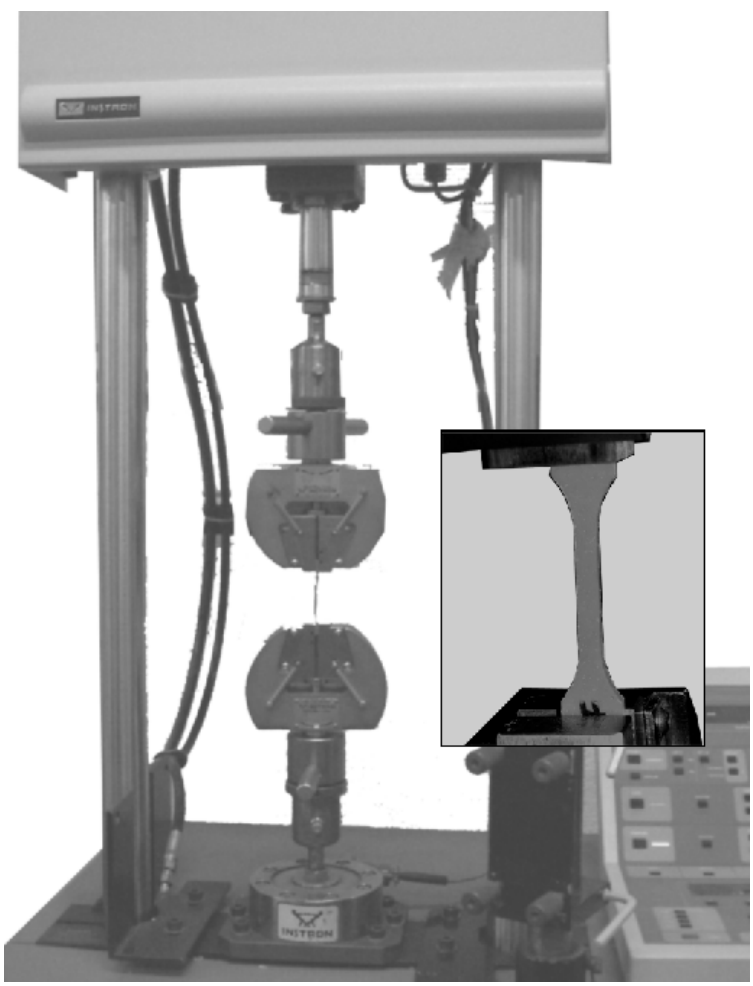

(a)

(b)

Figure 5: Instron 8511 Machine; (a) Front view, (b) Main component. 


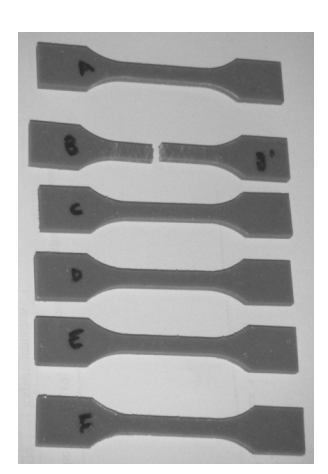

(a)

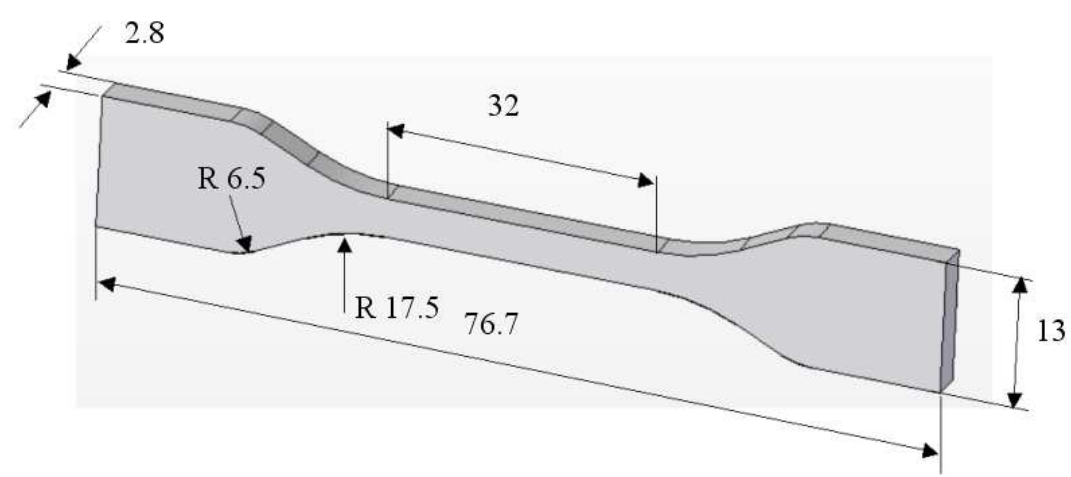

(b)

Figure 6: (a) Test specimen and (b) Dimensions (in mm).

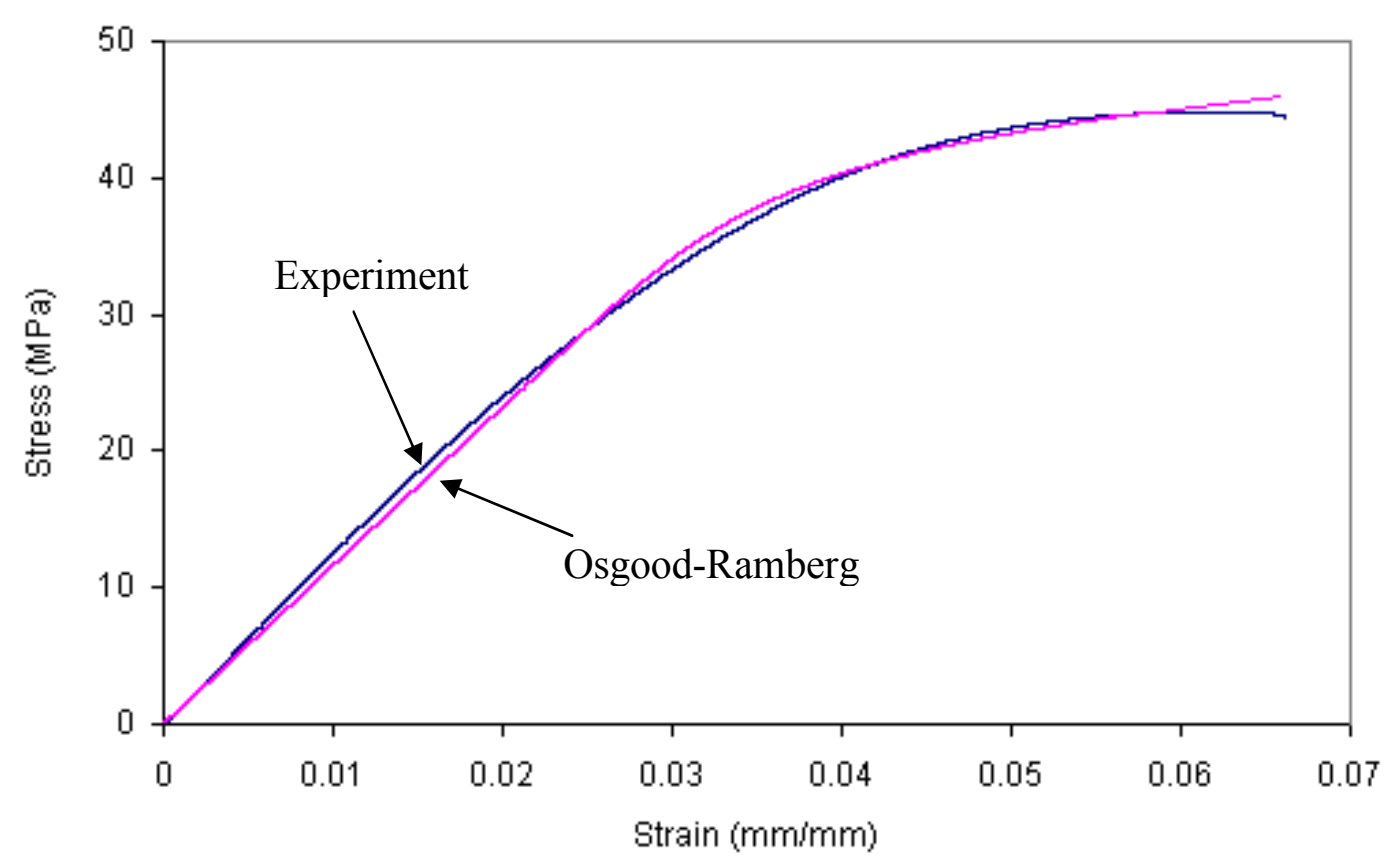

Figure 7: Curve fitting of stress-strain curve of bulk adhesive from tensile test 


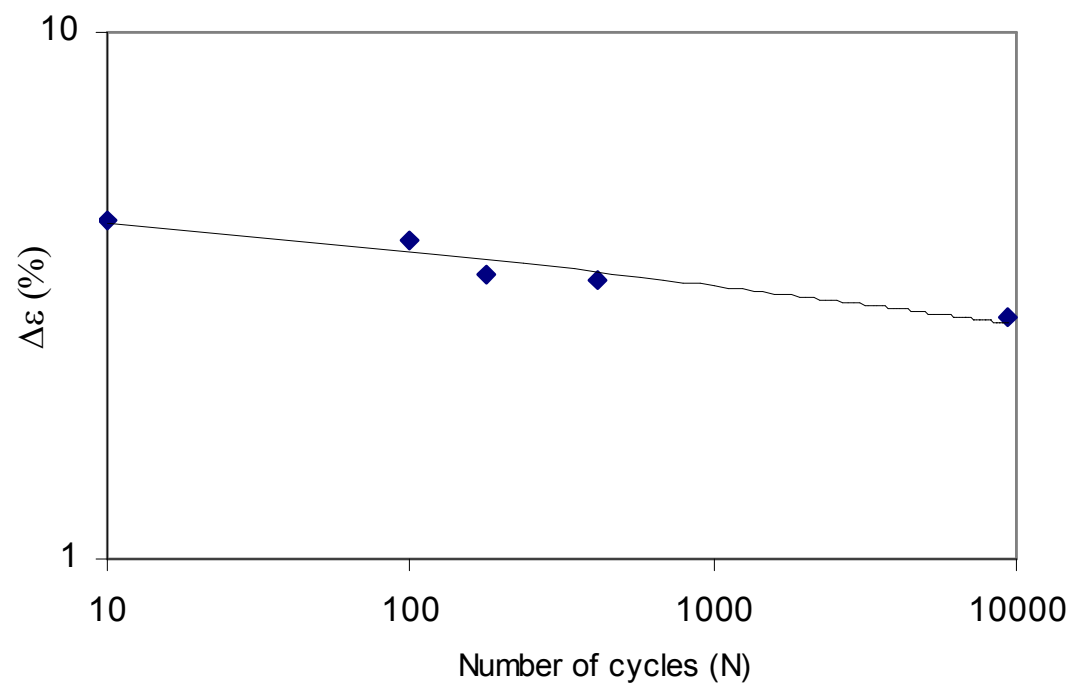

Figure 8: Strain range $\Delta \varepsilon$ function of $\log \left(N_{f}\right)$.

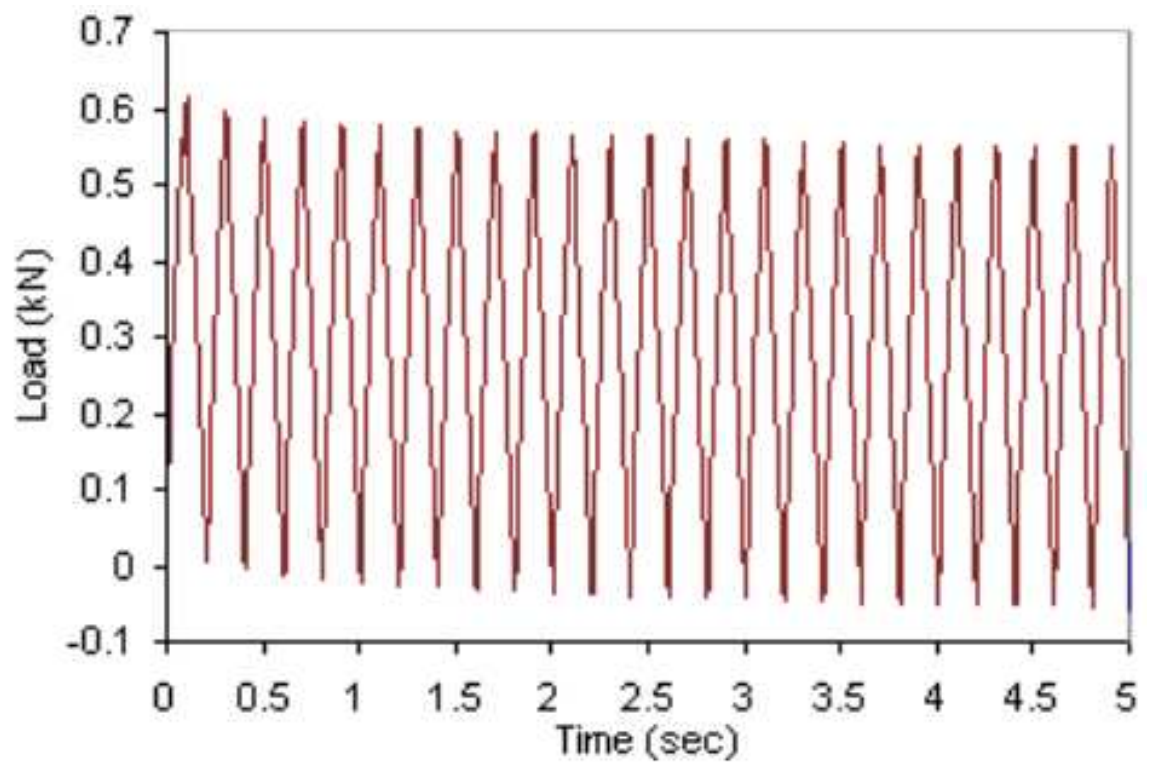

Figure 9: Sample of constant strain amplitude fatigue raw data. 


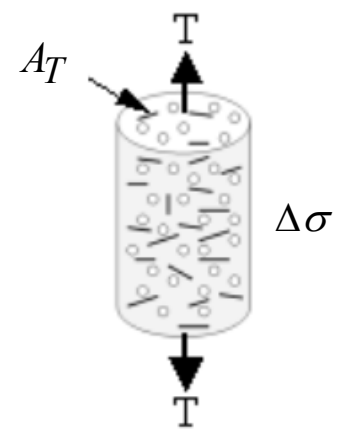

(a)

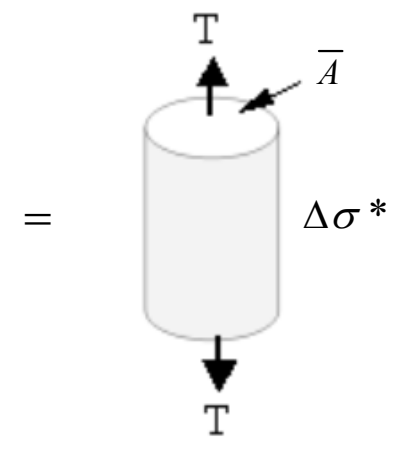

(b)

Figure 10: Two equivalent damage models: a) Bar with voids and cracks and (b) Bar without voids and cracks.

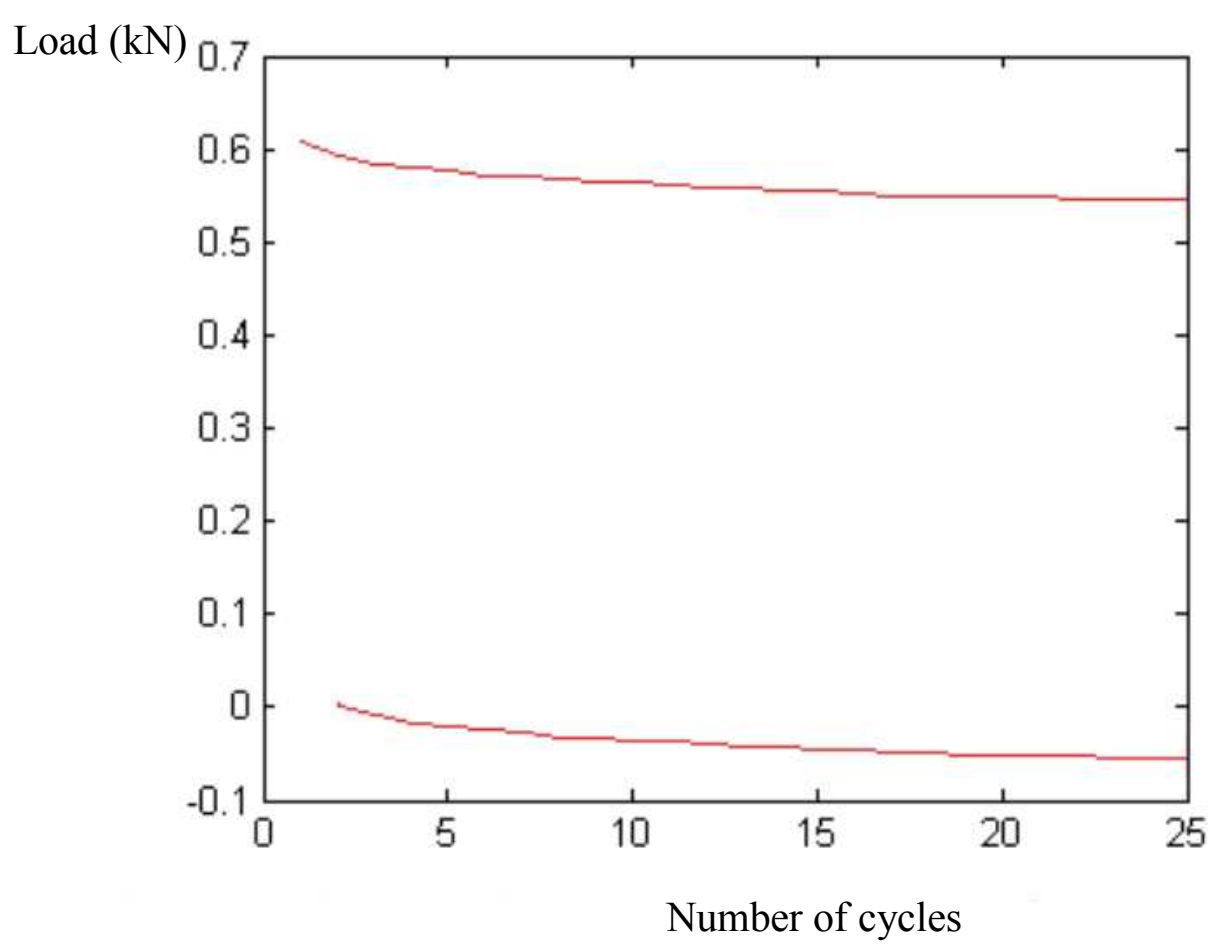

Figure 11: Extracted data from raw data using MATLAB code for $\Delta \sigma_{e q}^{*}=43.88 \mathrm{MPa}$ 


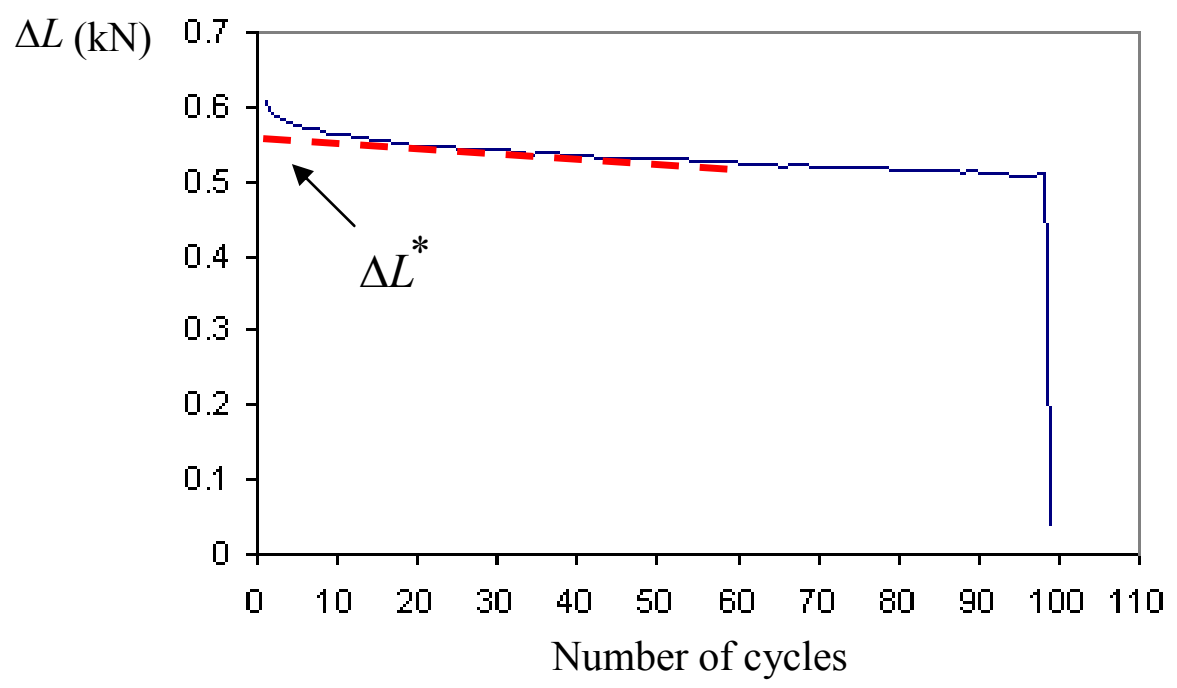

Figure 12: Load range, $\Delta L$, versus number of cycles for $\Delta \sigma_{e q}^{*}=43.88 \mathrm{MPa}$

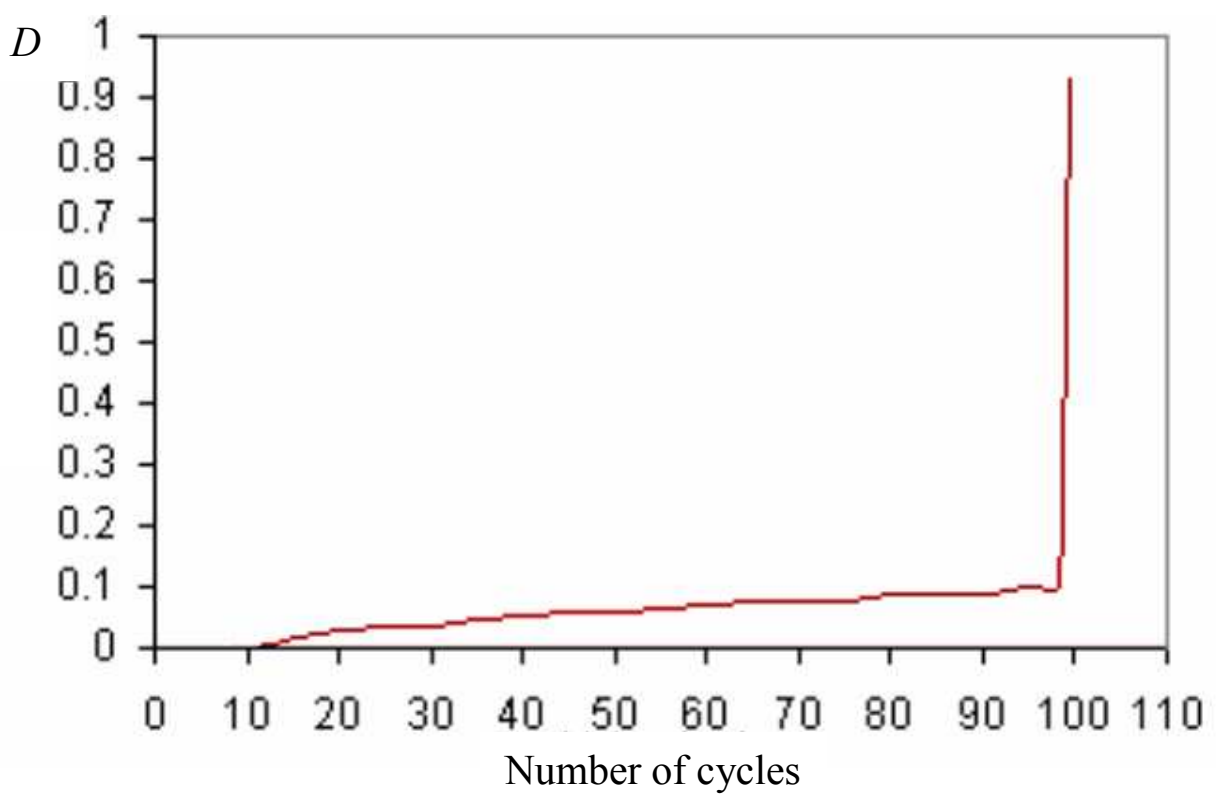

Figure 13: Damage value versus number of cycles for $\Delta \sigma_{e q}^{*}=43.88 \mathrm{MPa}$ 


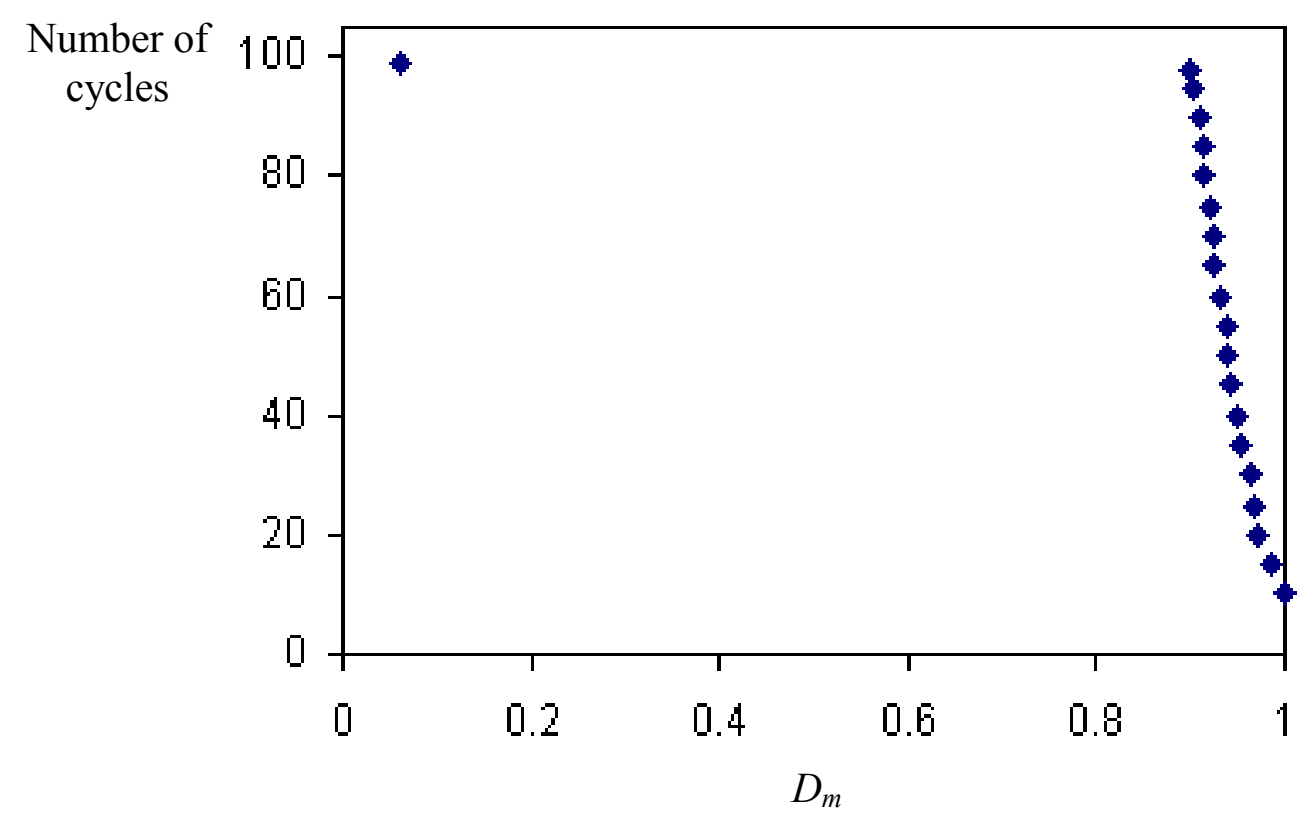

Figure 14: Number of cycles as a function of $D_{m}$ for $\Delta \sigma_{e q}^{*}=43.88 \mathrm{MPa}$ 


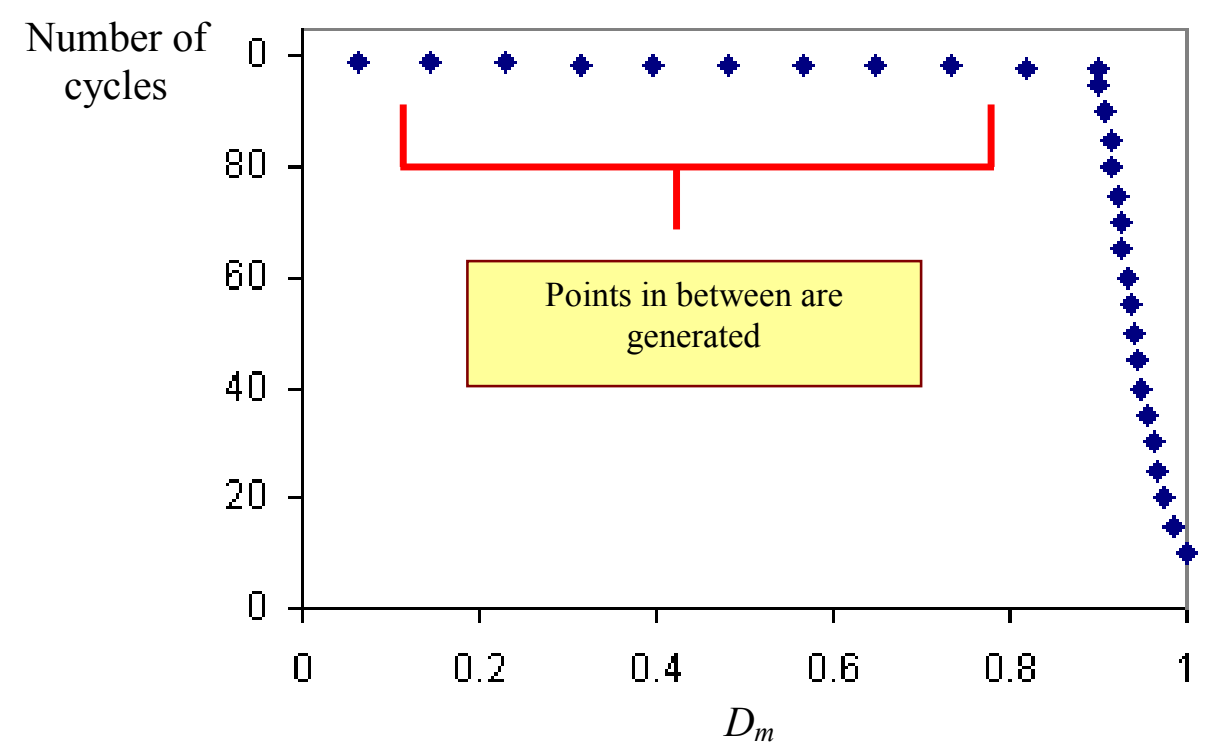

Figure 15: Number of cycles as a function of $D_{m}$ with generated points for $\Delta \sigma_{e q}^{*}=43.88$ MPa

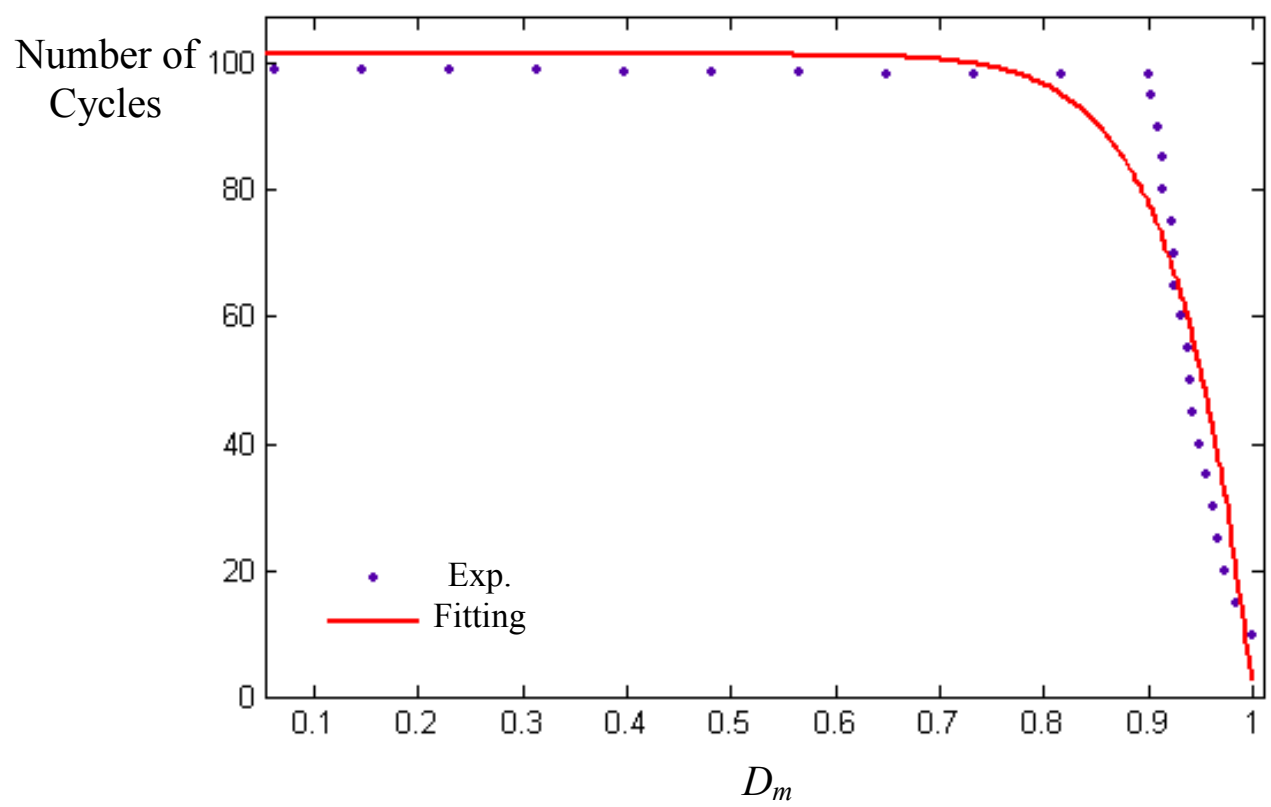

Figure 16: Fitting curve compared to experimental data for $\Delta \sigma_{e q}^{*}=43.88 \mathrm{MPa}$ 


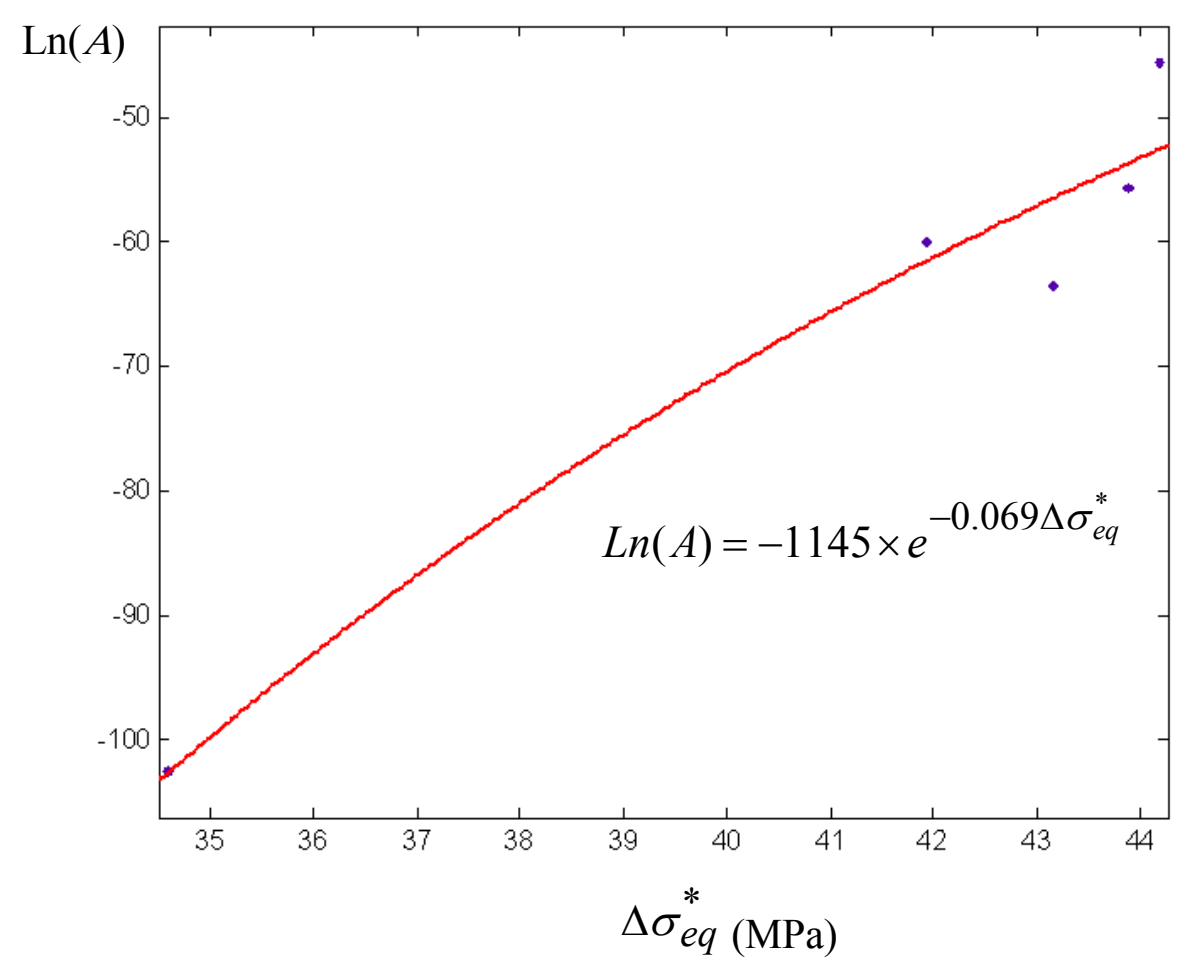

Figure 17: Damage parameter, $\operatorname{Ln}(A)$, versus stress range $\Delta \sigma_{e q}^{*}$

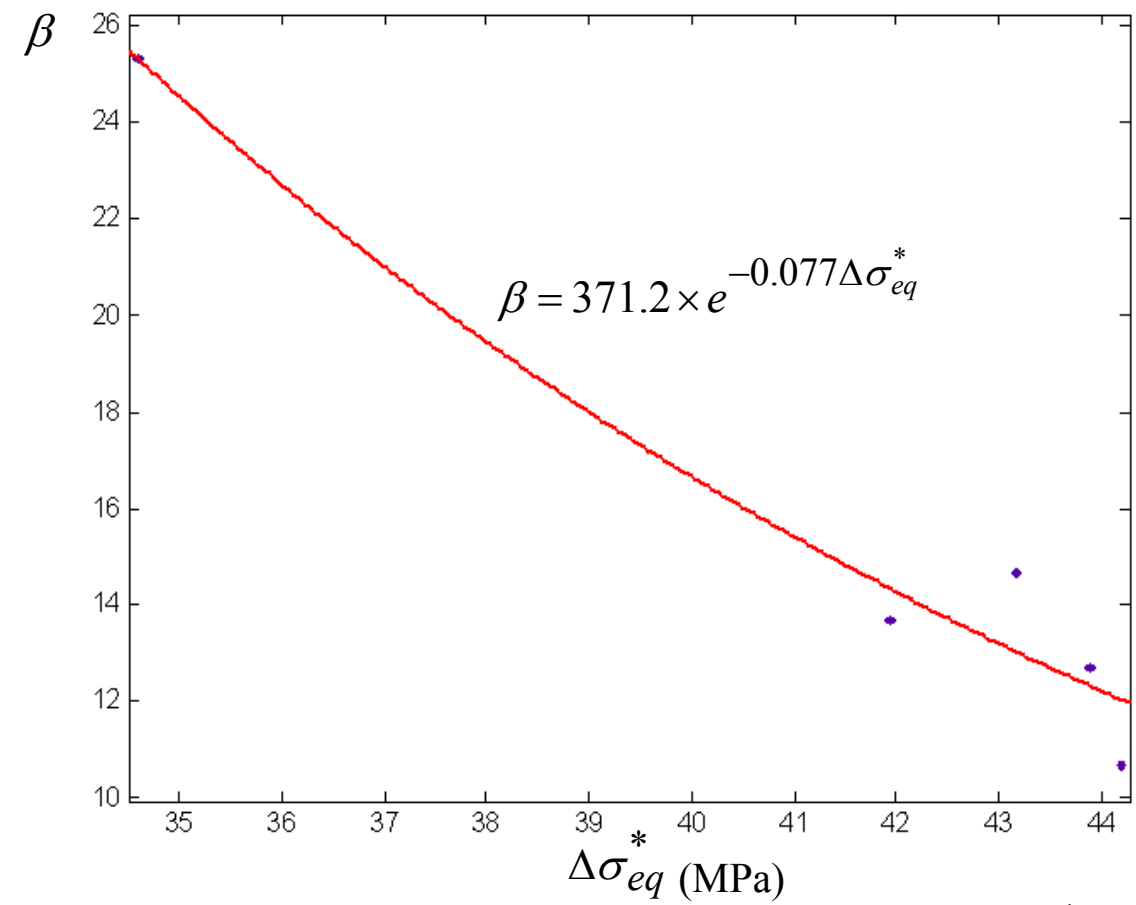

Figure 18: Damage parameter, $\beta$, versus stress range $\Delta \sigma_{e q}^{*}$ 


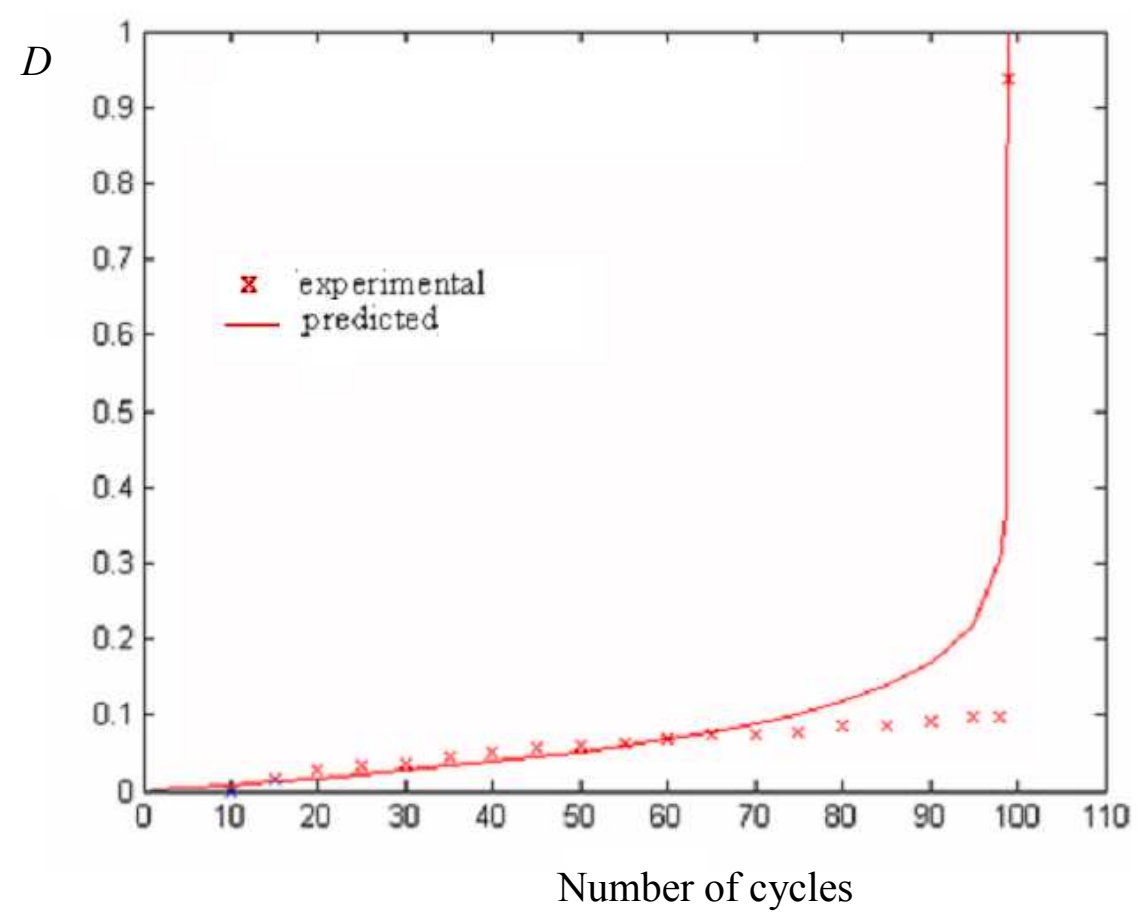

Figure 19: Damage value, experimental and predicted for $\Delta \sigma_{e q}^{*}=43.88 \mathrm{MPa}$

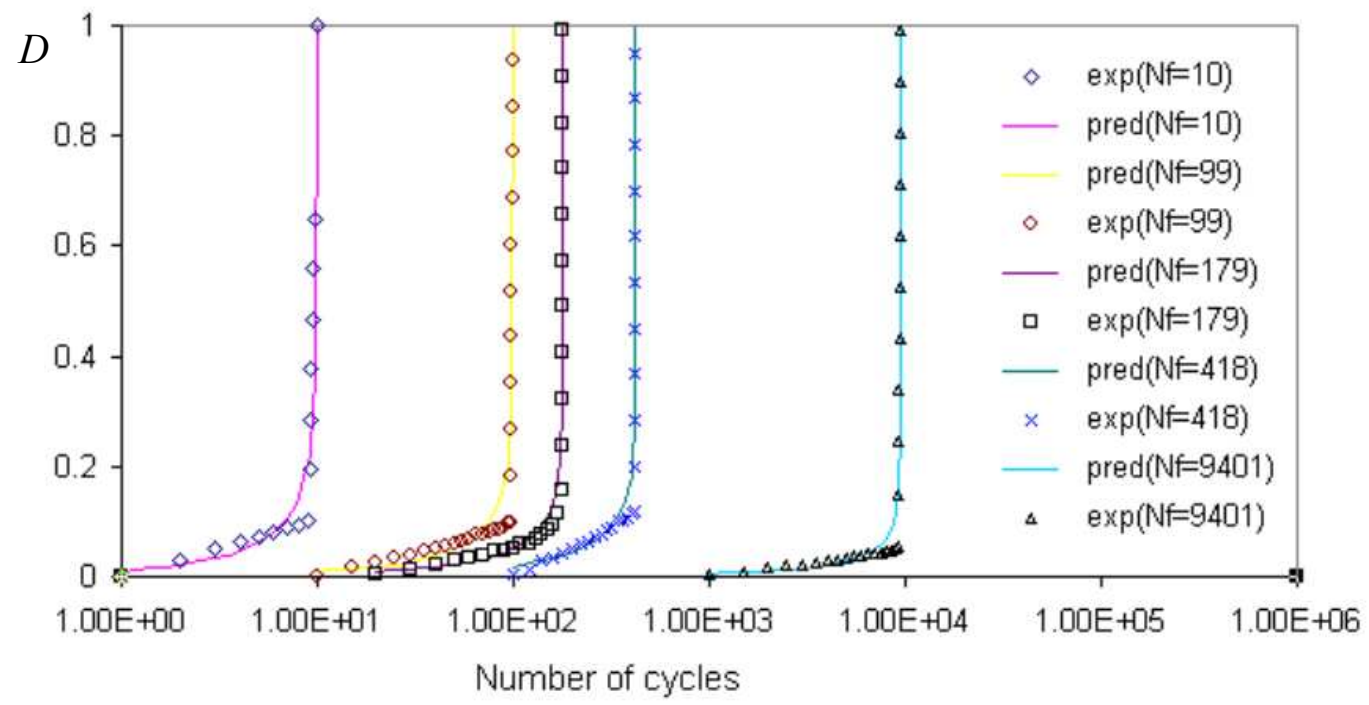

Figure 20: Comparison between experimental and predicted damage variables for all load range level 


\section{Appendix A}

MATLAB Code for curve fitting of damage model to experimental data

function dm10gen $(\mathrm{Dm}, \mathrm{N})$

$\%$ DM10GEN Create plot of datasets and fits

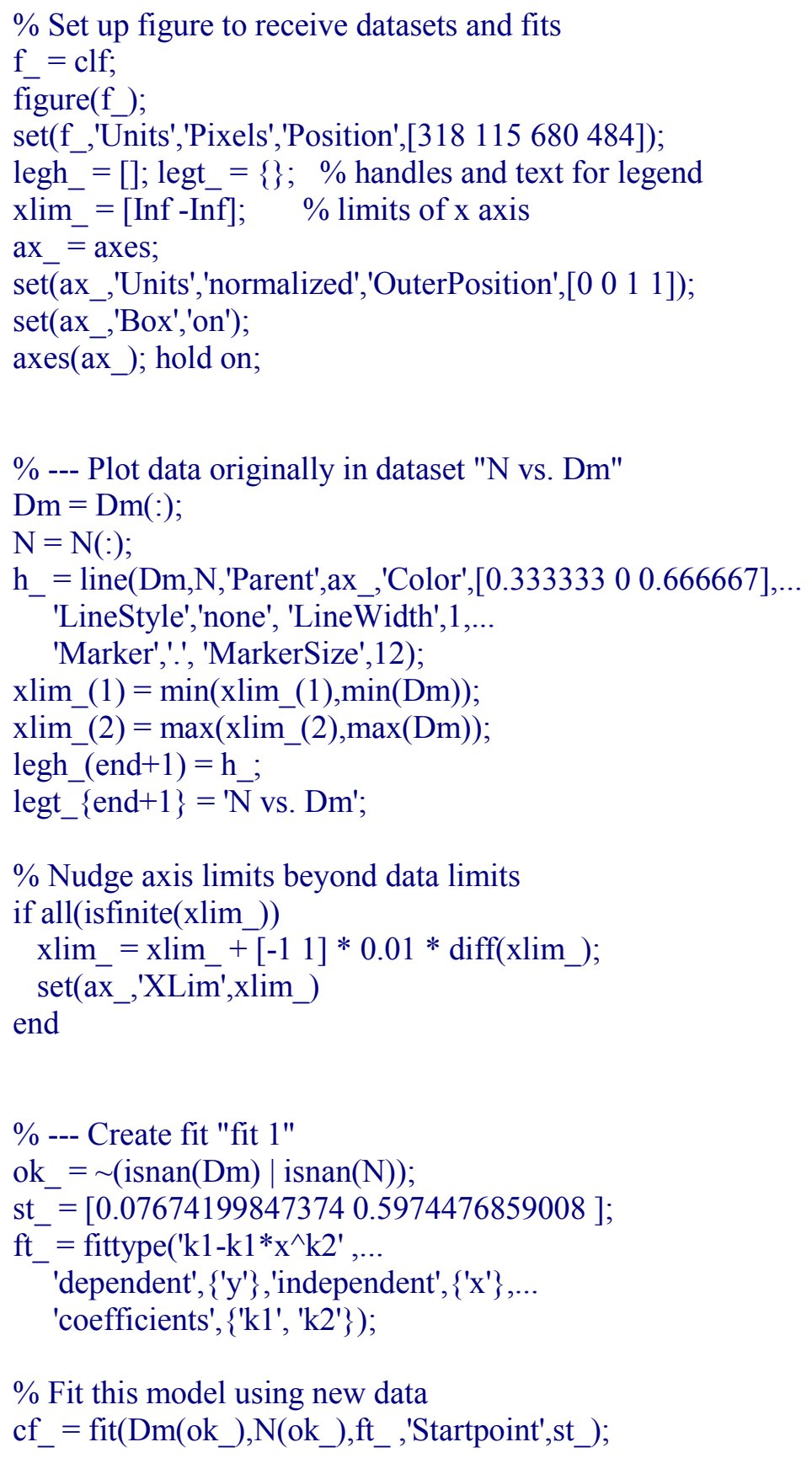


$\%$ Or use coefficients from the original fit:

if 0

$\mathrm{cv}_{-}=\{9.724102351622,11.75744857267\}$;

cf_=cfit(ft_cv_\{:\});

end

$\%$ Plot this fit

$\mathrm{h}_{-}=$plot(cf_,'fit',0.95);

legend off; \% turn off legend from plot method call

set(h_(1),'Color',,[1 00$], \ldots$

'LineStyle','-', 'LineWidth',2,...

'Marker','none', 'MarkerSize',6);

legh $($ end +1$)=h(1)$;

legt_\{end +1$\}=$ 'fit 1';

$\%$ Done plotting data and fits. Now finish up loose ends.

hold off;

h_= legend(ax_,legh_legt_,'Location','NorthEast');

set(h_,'Interpreter','none');

xlabel(ax_,"); $\quad \%$ remove x label

ylabel(ax_,"); $\quad \%$ remove y label 